\title{
Electrical impulses recharge spinal cord injury research
}

An injury to the spinal cord, once considered a lost cause, may no longer mean an inevitable slide into chronic illness and physical decline. Studies are increasingly supporting the once-controversial idea that exercise can improve sensory and motor function long after the initial injury.

The latest evidence comes from scientists who used electrical impulses during exercise therapy to stimulate muscles. That approach has been around for more than 30 years, but the cost of the machines-about $\$ 15,000$ each-and years of poor equipment design made it impractical.

Researchers at the Baltimore-based Kennedy Krieger Institute followed 48 people who were paralyzed an average of five years prior to treatment for nearly two years. Individuals randomly received either restorative therapyriding a specially constructed bicycle three times each week while their leg muscles are stimulated through electrodes placed on the skin's surfaceor stretching exercises. Of the restorative group, $40 \%$ regained some motor function such as the ability to walk without a walker or better bladder control as compared with only $4 \%$ in the stretch- ing group. Exercise also cut muscle spasticityuncontrollable jerky movements-by $47 \%$.

The therapy also boosted muscle mass by an average of $30 \%$ while trimming fat by an average of $44 \%$, factors that can cut the risk of diabetes and heart disease. "Those are benefits of exercise we know already," says Lead researcher John McDonald. "But exercise is never offered to paralysis patients."

More controversial is exactly how exercise influences recovery. Some scientists say physical activity merely strengthens long-atrophied neural connections. "I'm not surprised that people can regain some function," says Diana Cardenas, chief of rehabilitation medicine at the University of Washington. "If you stimulate the heck out of a muscle, you would expect it to get stronger."

But McDonald says his data suggest there's more going on. McDonald treated the late actor Christopher Reeve, who was paralyzed from the neck down after a horse-riding accident in 1995. Before he died in 2004, Reeve had regained sensation in $98 \%$ of his body and some motor function, McDonald says.
Reeve could, for example, stand unassisted in a swimming pool, breathe on his own for several hours without the aid of a respirator, and hold a glass. His recovery was especially remarkable because he began to improve after five years of exercise therapy, hinting that some nerves had regenerated. But critics say individual cases do not prove that recovery is possible in most people.

Mounting evidence from animal studies also supports the idea that physical activity promotes regeneration. For instance, Fred Gage at the Salk Institute in California has consistently shown that physical and mental activity substantially boost the birth and survival of nerve cells in rats.

McDonald's lab has found that when they electrically stimulated the hind limbs of injured rats, more than $32 \%$ of stem cells transplanted below the injury site had differentiated into neuronal cells as compared with only $9.1 \%$ in controls.

"McDonald's work has fostered a lot of interest in the field," says Randal Betz, chief of staff at Shriners Hospital in Philadelphia, "but we need more evidence."

Gunjan Sinha, Berlin

\section{Poor records pinpoint lack of attention to}

A new report on gender differences in granting decisions has uncovered large gaps in recordkeeping at several US science agencies. Advocates of gender equality are calling for better data, saying poor records make it impossible to determine whether agencies are complying with antidiscrimination laws.

The report, commissioned by the US Congress and released on 14 September, found that the Department of Defense and the Department of Energy collect little information on applicants' gender. The records are so poor that the RAND Corporation, a nonprofit research organization that led the study, could not analyze the agencies' decisions, according to principal investigator Susan Hosek. "We concluded this was going to be a nightmare of very questionable value so we just gave up," she says.

The National Science Foundation and the US Department of Agriculture had more complete data. At those agencies, the report found, women and men requested and received on average the same amount of money.

The group's analysis of the US National Institutes of Health (NIH) yielded some surprises. Based on grant applications from 2001-2003, women applicants received on average $83 \%$ of the funds awarded to male applicants, controlling for factors such as age and academic degree - and excluding the top one percent of large awards. Women received only $13 \%$ of those large awards. The report also revealed that women are less likely to reapply after being rejected their first year.

In response to the RAND report, the NIH on 7 October released its own analysis, which suggests that men and women are about equally likely to receive a grant in response to their application. In 2004, the success rates for grant applications were $23.9 \%$ for women and $25.2 \%$ for men. But the data suggest that women ask for less money-which could explain why they get less, says Robert F. Moore, a consultant for the $\mathrm{NIH}$ and former director of the agency's division of statistics and analysis.

Ultimately, neither the RAND report nor the NIH gets to the heart of the matter, says Donna Dean, president-elect of the Association for Women in Science. For instance, she says, it is unclear why so few women are in charge of large awards, such as multicenter endeavors. Do fewer apply, and if so, how can the NIH address that? Why do fewer women reapply after their grants are rejected? The data should also be broken down by specialty, she says.

The US National Academies is set to release a separate report at the end of the year that

\section{gender gaps in science}

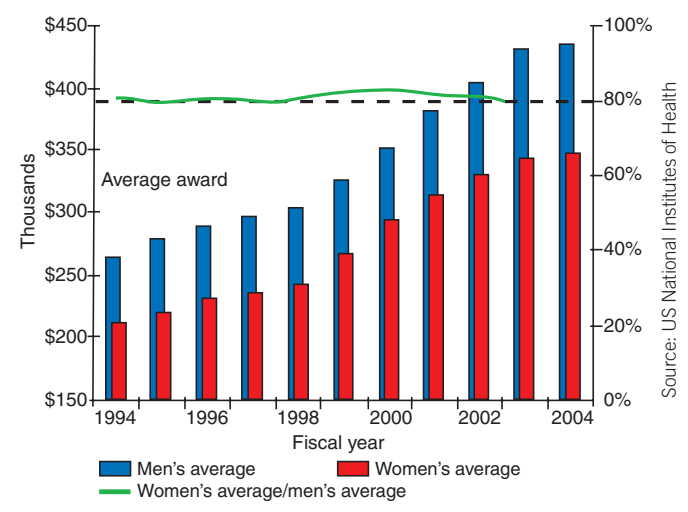

Money matters: In the past decade, NIH research grants to women have remained at about $80 \%$ of the size of research grants to men.

will address gender differences in areas such as faculty hiring, promotion and allocation of laboratory space.

Lack of data on gender of applicants makes it difficult to track compliance with Title IX, a US law that bars discrimination in education (Nat. Med. 11, 462; 2005), says Jocelyn Samuels, a Title IX expert at the National Women's Law Center in Washington, DC. Nondiscrimination policies may also compel agencies to address the issue of better recordkeeping, she says. "There is more than ample evidence that there is a problem here." Charlotte Schubert, Washington, DC 